\title{
The Effects of Performance Management and Development on the Performance of Modern Public Sector Organisations
}

Mrs Dolly Elizabeth Mthembu

Ms Vartikka Indermun

Academic- Management College of Southern Africa (MANCOSA)

\begin{abstract}
Performance management in the modern public sector organisations is the use of interrelated strategies and activities to improve the performance of individuals, teams and organisations. Performance management is an essential tool that is relevant at all levels in all public sector organisations. It provides a means to improve organisational performance by linking and aligning individual, team and organisational objectives and results. It also provides a means to recognise and reward good performance and to manage under-performance.This article explores the effects of performance management and development on modern public sector organisations including factors that limit the implementation of such measures in the promotion and retention of staff. Performance management in the modern public sector organisations can be described as 'work in progress.' Significant progress has been made but major challenges remain, especially on the issues of credibility and staff engagement.
\end{abstract}

KEYWORDS:Performance management, development, implementation, barriers, limitations, retention, promotion.

\section{Council for Innovative Research}

Peer Review Research Publishing System

\section{Journal: Journal of Social Sciences Research}

Vol. 8, No.1

jssreditor.cir@gmail.com

www.jssronline.com 


\section{Introduction}

Performance management in the modern public sector organisations is the use of interrelated strategies and activities to improve the performance of individuals, teams and organisations. Its purpose is to enhance the achievement of public sector organisational goals and outcomes for the government. Effective performance management requires a framework that integrates organisational, business and individual planning and performance. The review of relevant literatureshows that the positive effects of performance management and development on the performance of the modern public sector organisations include the achievement of high performance of the modern public sector organisations, the enhancement of accountability that leads to the improvement in service delivery and the improvement on the employee and management competencies.

\section{Achievement of High Performance of the Modern Public Sector Organisations}

Jamrog, Vickers, Overholt, \& Morrison(2008:29) posit that the use of performance management and developmental measures influences the attainment of high performance in the modern public sector organisations. They reason that performance management enhances the constant assessment and evaluation of the employees' competencies and subsequently the determining of the development measures which can be used to improve the employees' competencies and performance These authors construe that through such an approach, the management not only tends to be able to identify and correct deviations, but also improve on the skillfulness of the employees. In general, Jamrog et al. (2008:29) state that all these are associated with the resounding effects of improving employee performance and subsequently the attainment of high performance in the modern organisations. The notion of high performance is defined by Hughes (2010:199) to connote the resulting effects of performance improvement that influences the simultaneous delivery of all the three elements that include quality of products and services, outstanding customer value and sound financial performance. In other words, he construes that through performance management, the management is able to build the competencies that enables the employees to improve their efficiency and effectiveness to the levels that impact positively on the improvement of service delivery.

In the context of Hughes (2010:199) description, the quality of services in the public sector organisations refers to the extent to which the activities which are accomplished are directed towards the effective meeting of the needs expectations of the communities and the general public. He states that performance management ensures the accomplishment of these by facilitating not only on the evaluation of the employee's performance, but also the review of certain antecedents that include supporting work systems and methods as well as processes so as to ensure that the public sector organisations perform to their best. Despite noting that customer values are associated with developing and maintaining relationships with the customers and the general public, Hughes (2010:199) also points out that performance management enhances the evaluation of the dimensions that include;satisfaction, responsiveness, service, timeliness, convenience, courtesy, competence of employees and problem resolution.

In terms of the fostering of a sound financial management system, Hughes (2010:199) elaborates that when performance management is effectively accomplished in the modern public sector organisations, it can impact positively on revenue increment, the minimisation of costs, the establishment of a good management models and efficient systems.

Meanwhile, Macey and Schneider (2008:10) reveal that the introduction of the concept of performance management in the modern public sector organisations has facilitated the resolving of the challenge that most of the government departments have been faced with for decades regarding how to improve performance in all facets that include the efficiency of resources' usage, the delivery of programme outcomes, and the enhancement of transparency, accountability and citizens' participation. However, Jamrog et al. (2008:29) point out that the extent to which performance management would impact on the improvement of governments performance, depends on how the concept of 'one size fits all' is avoided by ensuring that performance management models adopted fit into each of the unique government departments.

In other words, these authors construe that the complexities associated with the variables in different government departments implies that an evaluation must be conducted so as to determine the performance management framework which would be suitable. In this endeavour, they propose that a range of the environmental factors that must be considered include leadership, the nature of a particular government department, the organisational culture, organisational history, the maturity of performance management systems and the workplace climate. In other words, Jamrog et al. (2008:29) argue that performance management in the modern public sector orgnaisations is able to contribute to the achievement of high performance because of its ability to continuously contribute to the improvement of the employee and management competencies.

\section{Employee and Management Competencies}

Jamrog et al. (2008:29) elaborate that in high performing public sector organisations, performance management is usually undertaken with the motive of identifying the inhibitors of the employees' performance and the determining of the training and development measures that must be undertaken. They stated that as a result of the application of such training and development measures, performance management impacts positively on the building of the employee and organisational competencies, and subsequently the improvement in the overall performance of the modern public sector organisations. Grant and Parker (2009:317) state that if performance management is well accomplished, improvements are usually realised on the key competencies that include the individual, attributes and knowledge of the employees. However, they cuation that the limitation of most of the modern performance management systems is that they are modelled to only examine the individual employee's performance. Yet, to improve the organisational competencies and the generall 
organisational pertformance, performance management must not only be directed towards improving the individual employee's performance, but also linked to the improvement of group performance. According to Grant and Parker $(2009: 317)$ this influences the creation of a coherent set of competencies that impact positively on the improvement of the performance of the modern public sector organisations.

Hughes (2010:199) noted that the improvement ofcompetencies and capabilities influence the overall improvement of service delivery in the modern public sector organisations. Hughes (2010:199) states that achieving specified goals and objectives means that the organisation is able to improve its service delivery as well. He elaborates that whether it is in the private or public sector, modern trends reveal that the meeting of the consumers' needs is the key to realizing general organizational success. He attributes his arguments to the fact that performance management systems enables organizations to constantly review their service delivery processes and where deviations are noted, necessary corrective measures are undertaken to ensure that the process is brought on track. Hand in hand with improving service delivery, Hughes (2010:199) also reveals that effective performance management system also influence cost reductions and reduces wastages by examining employees' behaviours and actions that result into waste and reducing efficiency and effectiveness.

The view that performance management impacts positively on the improvement of service delivery in the modern public sector organisations is further accentuated in the views of Parston and Goodman (2008:19)that performance management enhances the identification and elimination of individual and organisational deficiencies. They elaborate that whereas the individual employee deficiencies that can be identified and amelioratedthrough performance management include lack of skills, poor commitment and other personal challenges, the organisational deficiencies that can be identified and remedied through performance management encompass lack of effective leadership, poor motivation and poor work environment. Despite arguing that the identification and amelioration of these deficiencies enhance the improvement of the performance of the modern public sector organisations, these authors also revealed that performance management also contributes to the improvement of accountability in the modern public sector organisations.

\section{Improvement in Service Delivery}

Peters (2010:66) reveals that over the years, performance management and development were viewed as private sector concepts. Instead, they noted that the process for holding employees and managers accountable was limited to policy and regulatory measures. He explained that in the context of the different existing administrative laws, employees were required to accomplish activities within certain policy prescriptions with the effect that on failure, they were usually held accountable by either superiors or the parliament's public accounts committees or through the public ombudsman or a court of law. However, Peters (2010:66) points out that despite the deterring effects of these regulatory and policy measures, they were not adequate for identifying and facilitating the correction of deviations as the process for activities' accomplishment is still on-going on constrast, he highlights that the integration of the concept of performance management in the modern public sector organisation has contributed to the fullfilling of such gaps. Peters (2010:66) explains that unlike the accountability measures establishedthrough legal prescriptions, the use of performance management enables the managers toassess and evaluate the employees' performance as the process for activities' accomplishment is on-going. As compared to the legal and policy measures that only intervenes post the process of activities' accomplishments, he notes that performance management play proficient roles in the implementation of public sector programmes by ensuring continuous monitoring and intervention.

According to Peters (2010:66), this influences the correction of the devitaions that would have been more costly to remedy if earlier interventions were not made. This view is further distilled in the assertion of Marcus, Ashkenazi and McNulty (2009:10) with the integration of performance management in financial management, tendering processes and in the evaluation of the process of service delivery. There has been significant improvement in the accountability of public sector managers than ever before. These authors reason that this improvement in accountability influences the improvement of the mangaement capacity of the modern public sector organisations. Marcus et al. (2009:10) explains that management capacity connotes the competencies and dynamic capabilities which are necessary for the public sector organisations to achieve the outlined strategic goals and objectives. They elaborate that this improvement in management capacity arise from the fact that performance management enhances the assessment and improvement of the configuration of interrelationships between systems and subsystems that influence the ability of the public sector organisations to attain the outlined strategic objectives and goals.

Despite these positive effects of performance management and development, authors such as Chen and Chiu (2009:474), the Australian Government (AGRAGA) (2010) and Clardy (2007:339) point out that the process for the effective accomplishment of performance management in the modern public sector organisations is still undermined by a number of limitations.

\section{Factors that Limit the Implementation of the Measures for EPMDS in the Modern \\ PublicSector Organisations}

Theoretical analysis indicate that the factors that limit the implementation of the measures for employee performance management and development in the modern public sector organisations include; lack of appropriate principles for performance management and development, poor alignment of performance management processes with the strategic goals and risks of ratter's errors in performance measurement. The details of these factors are evaluated as follows.

\section{Lack of appropriate Principles for Performance Management and Development}


Clardy (2007:339) argues that although empirical research indicates that the concept of performance management and development has been widely integrated in the modern public sector organisations, its effectiveness remains widely limited due to lack of its structuring along certain principles. He reasons that while it is true that there are no uniform principles for ensuring the successful accomplishment of performance management, it is a prerequisite that it must be developed and applied in accordance with certain principles. Clardy (2007:339) emphasises that the design of the performance management framework along such principles influences the assurrance that it contributes to measuring what the public sector organisations aims to measure and improve.

In effect, he proposes that the key principles that must be considered during the design of performance management include; the development of a strategic approach to managing people, articulating and promoting key human resource management principles and values, raising the standards of training and development as a key element of the strategic human resource management process, highlighting the key human resource management capacity for evaluation and improvement, and integrating the core concept of performance appraisal. In terms of developing a strtaegic approach to managing people, Clardy (2007:339) argues that performance management will only impact positively on improving the performance of the modern public sector organisations, if the policies and practices for managing people are clearly aligned with the overall strategies for ensuring the quality, effectiveness and efficiency of the local government.

In a view echoed in Chen and Chiu's (2009:474) argument, Clardy (2007:339) further states that the establishment of a comprehensive performance management system must facilitate the linking and the interdependencies between the different human resource management areas. They add that further initiatives must also be undertaken to ensure that the human resources are developed and promoted as a matter of priority.

In a bid to ensure that the human resource management systems are able to effectively respond to the needs of the local government, Chen and Chiu (2009:474) propose that the local government authorities must determine the core elements that must be standardised across its different operations, and the elements that can be opened to flexibility. These authors note that while performance management is being accomplished, evaluations must also be conducted to determine how rules and regulations affecting the management of people can be reviewed and streamlined to ensure that such rules and regulations facilitate rather inhibit the effective performance of a government department. In a bid to determine how the humanresource management systems can be integrated with core values in each municipality, they suggest that line managers must be provided with sufficient autonomy so as to assess how such integration can be achieved.

While this is being accomplished, Chen and Chiu (2009:474) state that the embracement of a more devolved budgeting and tight accounting proceduresare some of the ways of allowing authority to be devolved to the line managers so that they can be able to manage the staff, determine appropriate staff size and allocate resources within an agreed resource base and a framework which sets out basic budgetary principles to which they must adhereto. Hand in hand with the taking of this measure, the Australian Government (AGRAGA) (2010) and Clardy (2007:339) reveal views that imply that for performance management and development to be effectively accomplished in the modern public sector organisations, there must also be clear articulation and promotion of the key human resource management principles and values. They highlight that the human resource management principles which must be considered during the design of the performance management system include fairness, equity, ethical conducts, efficiency, flexibility and accountbability.

At the same time, these authors reason that for performance management to contribute towards the improvementin the development of the employee's skills and competencies, then, focus must be directed towards the development of leadership and management skills and competencies at all levels of the structures of the public sector organisations. In addition to lack of appropriate principles for performance management and development, authors encompassing McBride (2008:69), Osborne (2010:229), and Pablo, Dewald and Casebeer (2007:687) also note that poor alignment of performance management processes with the strategic goals can also undermine the effectiveness of performance management and development in the modern organisations.

\section{Poor Alignment of Performance Management Processes with Strategic Goals}

Osborne (2010:229) reveals that in most of the studies which were conducted on performance management in the modern public sector organisations, it was noted that performance management has not been able to produce the desired results because of lack of alignment of the performance management processes with the objectives of the public sector organisations. He states that the consequences of these have been latent in the failure of most of the performance management system to be used as a measure for influencing the attainment of the outlined goals in the modern public sector organisations. Instead, he points out that performance management is percieved as more of a separate process which is detached from the rest of the organisational processes. Osborne (2010:229) highlights that of recent, there has been a plethora of many governments having to sign performance agreements with ministers and the senior government officials, and at the lower levels of the governmental structures, there has been poor implementation with the effect that most of the employees tend to view performance management as more of a budern than a process that all would seek to benefit from.

To a significant extent, such a view illustrates why Pablo et al. (2007:687) stated that since most of the employees in the modern public sector organisations have not been able to identify the link between performance management and their individual professional and career development, the emerging negative attitudes has rendered it difficult for the management to successfully conduct performance management among the ordinary employees. Pablo et al. (2007:687) further indicate that studies have also revealed that due to the poor motivation and commitment of the employees, it has also been difficult for most of the public sector organisations to inculcate a culture of performance management. These 
authors point out that lack of such a culture renders it difficult for the creation of the environment that facilitates the effective accomplishment of performance management.

Besides such cultural related issues, they also highlighted that the poor management of the process of performance management has also rendered it difficult for performance management to gain acceptance among the ordinary employees. These authors attribute their arguments to the fact that evidence from studies conducted in the modern public sector norganisations indicated that more skillful employees expressed dissatisfactions due to the fact that trends indicate that even the employees who are more skilled and performing well are usually rewarded more than the more competent ones. In that effect, they stated that most of the employees feel that performance management has lot relevance since it is more of a political tool to fight political wars.Meanwhile, McBride (2008:69) also indicates that the effectiveness of performance mangaement in the modern public sector organisations has been undermined by the fact that during performance management, most of the managers have been more faster in the evaluation of the employee's performance than in giving feedback to the employees. He posits that such approach demotivates the employees as they fail to note the areas that they have been performing better or poorly so as to determine how to improve. Hand in hand with poor alignment of performance management processes with the strategic goals. Noe, Hollenbeck, Gerhart and Wright (2008:381) also noted that risks associated with ratererrors in performance management can also mar the effectiveness of performance management in the modern organisations.

\section{Risks of Rater Errors in Performance Measurement}

Noe et al. (2008:381) research consistently reveals that human beings have tremendous limitations in processing information and because of this they end up using simplifying mechanisms to make their judgments. They also end up making subjective measures of performance which can lead to rater errors, which in the end, can distort evaluations. These authors highlight that the human errors that are encountered during rating period include; unclear standards manifested in inconsistency of standards of raters, hallo effect that arises when the rater erases one character with another, central tendency when rater finds it unpleasing/ difficult to evaluate employee higher or lower than the others even if there is a huge difference in performance, leniency or strictness attributable to the fact that the inexperienced supervisors appraise too leniently- easy even if not deserved gain popularity, feeling unfair, regency associated with the fact that recent performance can mislead evaluator's perception, to fight this regular and frequent performance evaluation throughout, and the fact that supervisory bias may be influenced by characteristics such as race, age, gender etc.

Noe et al. (2008:35) state that in a bid to avoid these challenges, performance measurement can take place effectively if the company has conducted job analysis, and job design, have explained what kind of performance they expect from employees and the techniques that would be used to measure performance. Noe et al. (2008) identified five criteria for effective performance management systems; i.e. strategic congruence, validity, reliability, acceptability and specify. These authors elaborate that strategic congruence elicits job performance management that is congruent/consistent with the organisation's strategy, goals and the culture. It emphasises on the need for performance management system to guide employees in contributing towards organisational success and the behaviours that relate to attainment of critical success factors.

Validity is concerned with maximising the overlap between actual job performance and the measure of job performance. It is the extent to which a performance measure assesses all relevant and only relevant aspect of performance. The performance measure should seek to minimise contamination with the effect that the criteria should measure performance that is strongly affected by things beyond the control of the individual employee. Reliability refers to the consistency of performance measure. Noe et al. (2008:35). The measure should be reliable over time, one need to measure performance consistently across time. Acceptability refers to the acceptance by the end user of the performance measure.

This is the extent to which a performance measure is found to be satisfactory or user friendly by those who use it. Fairness should be noted by those being evaluated (Noe et al., 2008:35).Research suggests that performance management systems that are perceived as unfair are likely to be legally challenged, be used incorrectly and decrease employee motivation to improve. Specify is defined as the extent to which a performance measure gives detailed guidance to employees about what is expected of them and how they can meet these expectations. It is relevant to both strategic and developmental purposes of performance management. If the measure does not specify what the employee can do to achieve its strategic goals, it does not achieve strategic goals. If it fails to identify employee performance problems, it is difficult for employees to improve their performance Noe et al., (2008:35). In other words, they concur with Price, Mores and Elliotte (2011:69) and Sedgwick (2010:14) that such biasness in the performance management process may not only lead to declining employee satisfaction and motivation, but also resistance that can undermine the creation of an environment and climate that foster the effective accomplishment of performance management. According to the Cabinet resolution 39 of (2007:1-2), EPMDS is aiming at the following, planning employees performance, managing employees performance, and improving employee performance, it is further aiming at optimizing every employee's output in terms of quality and quantity, thereby improving the Department's overall performance and service delivery.

\section{Conclusion}

In the broadest sense almost every action and behaviour in the organisation can enhance or dilute performance. Ever public organisation should strive to achieve the greatest possible consistency across values, actions and decisions including recruitment and promotion decisions, performance pay decisions, and all rewards including expensive development opportunities. In other words modern public sector organisations should engender a culture where people 
are motivated and confident that overall governance is fair and should strive continuously to narrow the gap between rhetoric and reality.

\section{BIBLIOGRAPHY}

1. Australian Government Reform of Australian Government Administration (AGRAGA) (2010) Ahead of the Game: Blueprint For The Reform Of Australian Government Administration. Canberra, Australia: Commonwealth of Australia.

2. Chen, C. C. \& Chiu, S. F. (2009) The Mediating Role of Job Involvement in the Relationship Between Job Characteristics and Organisational Citizenship Behavior. The Journal of Social Psychology. 149, 474-494.

3. Clardy, A. (2007) Strategy, Core Competencies and Human Resource Development. Human Resource Development International. 10(3), 339-349.

4. Grant, A. M. \& Parker, S. K. (2009) Redesigning work design theories: The rise of relational and proactive perspectives. Academy of Management Annals. 3, 317-375.

5. Hughes, O. (2010) Does Governance Exist? In S. P. Osborne (Ed.), The New Public Governance: Emerging Perspectives on the Theory and Practice of Public Governance. Abingdon, Oxon: Routledge.International Journal of Public Sector Management, 22(6): 478498.

6. Jamrog, J. J., Vickers, M., Overholt, M. H. \& Morrison, C. L. (2008) High-Performance Organisations: Finding the Elements of Excellence. People \& Strategy. 31(1), 29-38.

7. Macey, W. H. \& Schneider, B. (2008) The Meaning of Employee Engagement. Industrial and Organisational Psychology. 1(3-30).

8. Marcus, L. J., Dorn, B., Ashkenazi, I., Henderson, J. \& McNulty, E. J. (2009) MetaLeadership: a Primer, National Preparedness Leadership Initiative. Harvard School of Public Health and Kennedy School of Government, Harvard University.

9. McBride, D. (2008) 'Strategic Management Model for Public Organisations: Looking for Effective, Efficient, Transparent, Ethical, and Accountable Organisations', Syracuse University, Maxwell School of Citizenship and Public Affairs.

10. Noe, R.A., Hollenbeck, J.R., Gehart, B. \& Wright, P.M. (1998) Human Resource Management: Gaining a Competitve Advantage.McGraw- Hill Irwin, New York.

11. Osborne, S. P. (2010) The New Public Governance: Emerging Perspectives on the Theory and Practice of Public Governance. Abingdon, Oxon: Routledge.

12. Pablo, A. L., Reay, T., Dewald, J. R. \& Casebeer, A. L. (2007) Identifying, enabling and managing dynamic capabilities in the public sector. Journal of Management Studies. 44, 687-708.

13. Parston, G. \& Goodman, J. (2008) 'High-Performance Government Organisations: Principles for Creating Public Value'., Accenture.

14. Peters, B. G. (2010) Meta-Governance and Public Management. In S. P. Osborne (Ed.), The New Public Governance: Emerging Perspectives on the Theory and Practice of Public Governance. Abingdon, Oxon: Routledge.

15. Price, M., Mores, W. \& Elliotte, H. M. (2011) Building High Performance Government Through Lean Six Sigma: A Leader's Guide to Creating Speed, Agility, and Efficiency. New York: McGraw Hill.

16. Sedgwick, S. (2010) Australian Public Service reform: The past, the present and the future. Roundtable Seminar-Bureaucratic Reform Dialogue, MenPAN Conference Facility, Jakarta. 